\title{
OLANZAPINE COMBINED WITH STANDARD ANTIEMETIC REGIMENS FOR PREVENTION OF CHEMOTHERAPY THERAPY-INDUCED NAUSEA AND VOMITING: A SINGLE-CENTER EXPERIENCE FROM SOUTH INDIA
}

\author{
EMMANUEL JAMES ${ }^{1 *}$, DRISYA PM ${ }^{1}$, WESLEY M JOSE ${ }^{2}$ \\ ${ }^{1}$ Department of Pharmacy Practice, Amrita School of Pharmacy, Amrita Vishwa Vidyapeetham, Amrita University, AIMS Health Science \\ Campus, Kochi - 682 041, Kerala, India. ${ }^{2}$ Department of Medical Oncology \& Hematology, Amrita Institute of Medical Sciences \& Research \\ Centre, Amrita Vishwa Vidyapeetham, Amrita University, AIMS Health Science Campus, Kochi, Kerala, India. \\ Email: emmanuelj@aims.amrita.edu
}

Received: 03 April 2017, Revised and Accepted: 28 July 2017

\section{ABSTRACT}

Objectives: Olanzapine, an antipsychotic agent, exhibits significant antiemetic properties due to its inhibitory activity on neurotransmitters at multiple receptors involved in chemotherapy-induced nausea and vomiting (CINV). CINV can have an immensely negative impact on patient's quality of life (QOL) and daily activities. Our objectives were to determine the effectiveness of adding olanzapine to standard antiemetic regimens for the prevention of CINV in cancer patients and to compare the QOL of such patients with those receiving standard antiemetic regimens.

Methods: A prospective, observational, cohort study was done on patients receiving either highly or moderately emetogenic chemotherapy (MEC). The patients who received only the standard antiemetic regimens were considered as the control group and those who received $10 \mathrm{mg}$ of olanzapine once daily on days 1-5 of chemotherapy in addition to the standard antiemetic regimens were considered to be the study group. The patients were assessed for grades of nausea and vomiting using National Cancer Institute common terminology criteria for adverse events and for QOL using European Organization in Research and Treatment of Cancer QOL questionnaire.

Results: Patients were evaluated for a total of 168 cycles of chemotherapy. Compared to the control group, the study group patients showed significant improvement in response to acute nausea ( $p=0.02)$ but not in acute vomiting $(p=0.09)$. However, response to delayed nausea and vomiting improved significantly ( $p=0.004$ and $p=0.05$, respectively). The QOL of study group patients showed significant improvement in functional scales and symptom scales $(\mathrm{p}<0.02)$. Global health status also increased significantly $(\mathrm{p}=0.02)$ in the study group patients.

Conclusion: Olanzapine containing pre-medication regimens can reduce acute and delayed nausea and delayed vomiting and improve the QOL of cancer patients receiving highly or moderately emetogenic chemotherapeutic agents as compared to the standard pre-medication regimens.

Keywords: Adverse events, Chemotherapy-induced nausea and vomiting, Effectiveness, Olanzapine, Quality of life.

(c) 2017 The Authors. Published by Innovare Academic Sciences Pvt Ltd. This is an open access article under the CC BY license (http://creativecommons. org/licenses/by/4. 0/) DOI: http://dx.doi.org/10.22159/ajpcr.2017.v10i11.18864

\section{INTRODUCTION}

Chemotherapy-induced nausea and vomiting (CINV) are severe distressing adverse effects experienced by cancer patients receiving chemotherapy. Nausea and vomiting associated with cancer chemotherapy is distinct from typical nausea and vomiting that many people experience in their normal daily life. CINV can have an immensely negative impact on the patients' quality of life (QOL) and daily activities [1-5]. It can have a number of clinical implications for patients, including non-compliance with treatment, unwillingness or inability to eat and/or drink, and nutritional deficits. In most of the cases, sufferings experienced by cancer patients have been related to QOL to a great extent, and hence measurement of QOL can be used as an outcome measure to compare the effectiveness of different antiemetic treatment regimens [6,7].

The goal of antiemetic therapy is to reduce or negate nausea and vomiting associated with chemotherapy. A number of antiemetic regimens exist but are not fully effective. The most commonly used antiemetics such as 5-hydroxytryptamine-3 $\left(5 \mathrm{HT}_{3}\right)$ antagonists, dexamethasone, or neurokinin-1 receptor antagonists prevent emesis only in $60-70 \%$ of cancer patients receiving highly emetogenic chemotherapy (HEC) $[8,9]$. Hence, new drugs and regimens are being explored for more effective control of nausea and vomiting. Olanzapine in lieu of its inhibitory activity on neurotransmitters at multiple receptors involved in CINV, especially at D2 and 5-HT3 receptors, may exhibit significant antiemetic properties [10-12]. Hence, addition of olanzapine to standard antiemetic regimens may improve control of nausea and vomiting in cancer patients receiving highly or moderately emetogenic chemotherapeutic agents. As a result of the reduction in nausea and vomiting, the QOL of the patients may improve [7]. Improved QOL during chemotherapy is bound to increase the confidence of the patients, improve compliance to treatment, and ultimately result in better clinical efficacy. Often, the cancer patients have some symptoms of depression and anxiety, and olanzapine can also exert an antidepressant effect in these patients [13,14]. Although there are studies [15-20] describing the use of olanzapine for prevention of CINV, there is scarcity of data on Indian patients. Hence, our study was undertaken to compare the effectiveness of olanzapine containing antiemetic regimens with standard regimens for the prevention of CINV and to compare the QOL of patients between the two groups.

\section{METHODS}

A prospective observational study was carried out on cancer patients receiving highly or moderately emetogenic chemotherapy at the Department of Medical Oncology and Hematology of Amrita Institute of Medical Sciences and Research Centre, Kochi, India, from October 2013 to June 2014. This study was approved by the Institutional Review Board, and informed signed consent was obtained from all the study 
participants. Chemotherapy-naïve patients aged 18-65 years receiving treatment with highly or moderately emetogenic chemotherapeutic drugs and no known hypersensitivity to olanzapine or $5-\mathrm{HT}_{3}$ receptor antagonists were included. Patients on treatment with an antipsychotic agent or with a known history of psychiatric disease, diabetes, or those receiving minimal to low-risk emetogenic chemotherapeutic drugs were excluded from the study. Patients on concurrent or prior abdominal radiation therapy were also excluded. The use of olanzapine was at the discretion of the treating physicians, which is the routine practice in the department.

The European Organization in Research and Treatment of Cancer QOL Questionnaire (EORTC QOL) version 3.0 [21-24] was used for the assessment of QOL and Common Terminology Criteria for Adverse Events (CTCAE) version 4.0 [25] was used to grade nausea and vomiting. As per the CTCAE guidelines, the severity of nausea is ranked into three grades (1-3) and vomiting into five grades (1-5) with increasing severity.

The study patients who received the first cycle of chemotherapy with highly or moderately emetogenic agents were provided with EORTC QOL questionnaire in the language of their choice (Malayalam or English) and a form for assessment of acute and delayed CINV. These were collected back during the second cycle and they were provided with fresh QOL questionnaire and forms. This was repeated for a total of four cycles. The pre-medications and the chemotherapy regimens given to the patients were blinded to the investigators until all the four cycles of chemotherapy, and data collection on grades of nausea and vomiting and QOL of patients were completed. All the patients who received $10 \mathrm{mg}$ of olanzapine once daily orally on days 1-5 along with standard antiemetic regimens were included in the study group (olanzapine arm), whereas the control group patients consisted of those receiving antiemetic regimens without olanzapine. The standard antiemetic regimen consisted of ondansetron $16 \mathrm{mg}$ or palonosetron $0.25 \mathrm{mg}$ in combination with dexamethasone 8-12 mg. Chemotherapeutic regimens received by the study group patients were matched with those of the control group patients. For this, the patients in the control group were stratified into 6 groups based on the six chemotherapy combinations received by the study group patients. A number of patients equal to the study group taking these six types of chemotherapy regimens were chosen by random sampling of the 124 patients who received only the standard antiemetic regimens to form the control group. The scores for EORTC QOL questionnaire were calculated and analyzed. Nausea or vomiting occurring in $\leq 24 \mathrm{hrs}$ of chemotherapy was designated as acute while those occurring within 25-120 hrs were considered delayed occurrence [26,27]. Patients were also asked to report other adverse effects such as sedation, increase in appetite, or occurrence of any other untoward effects. After the chemotherapy, patients were also monitored for body weight and laboratory parameters such as fasting blood glucose levels and lipid profiles. The outcome of treatment was evaluated by comparing the percentage of total chemotherapy cycles in which the patients were free of nausea and vomiting and in which the patients had high QOL in the study and control groups. The secondary end point for outcome evaluation was attainment of complete response which was defined as no emesis and no use of rescue medications during the acute, delayed, or the overall period of 0-120 hrs after chemotherapy during each cycle of therapy.

The collected data were compiled using Microsoft Excel and analyzed using Statistical Package for the Social Sciences software version 20. Descriptive statistical parameters were calculated and significance of the study results was assessed by independent t-test.

\section{RESULTS}

A total of 145 eligible patients completed 4 cycles of chemotherapy during the study period. Only 21 patients were found to have received the pre-medication regimen containing olanzapine and they were included in the study group. Hence, an equal number of patients receiving similar chemotherapy as the study group but with the premedication regimens without olanzapine were identified from the remaining 124 patients. The control and study group patients each completed 84 cycles of chemotherapy. Majority of patients in both groups (38.1\% in control group vs. $33.3 \%$ in the study group) received palonosetron $0.25 \mathrm{mg}$ in combination with dexamethasone $12 \mathrm{mg}$ and remaining received ondansetron $16 \mathrm{mg}$ with dexamethasone $8 \mathrm{mg}$. Both the control and study group patients were also comparable ( $p>0.05)$ with respect to age, gender, and chemotherapy regimens received (Table 1). Majority of patients receiving chemotherapy in the control group and study group was in the age range 45-62 years.

Table 2 describes the distribution of chemotherapy cycles of patients experiencing acute or delayed nausea after chemotherapy. The study group patients were free of both acute and delayed nausea in $64.3 \%$ of cycles in comparison to $13.1 \%$ in the control group ( $p=0.003$ ). Similarly, there was a significant increase in the number of patients free of both acute and delayed vomiting in the study group (Table 3 ).

Only $1.44 \%$ of patients experienced Grade 1 nausea in study group, whereas $17.4 \%$ of patients suffered Grade 1 nausea in the control group ( $\mathrm{p}=0.003$ ). Grade 2 nausea was experienced by $13.9 \%$ of patients in study group and $85.9 \%$ of patients in the control group $(\mathrm{p}=0.019)$. The control group had $0.24 \%$ of patients experiencing Grade 3 nausea, but none of the patients in the study group reported the same (Fig. 1). About $96.4 \%$ of patients in the study group were free of vomiting in comparison to $71.4 \%$ of the control group ( $\mathrm{p}=0.015)$ (Fig. 2). Complete control of nausea in the acute phase, delayed phase, and overall period of $0-120$ hrs was achieved in $94 \%, 65.5 \%$, and $64.3 \%$ of chemotherapy cycles, respectively, in the olanzapine arm against $76.1 \%, 15.5 \%$, and $11 \%$ in the control arm.

The QOL of patients was assessed in all the 168 cycles of chemotherapy. Significant improvement in QOL was observed in the study group patients in the domains of physical functioning $(\mathrm{p}<0.0001)$, role functioning $(\mathrm{p}=0.005)$, and emotional functioning $(\mathrm{p}=0.0005)$ as compared to the control group patients (Fig. 3). The study group patients exhibited significant improvement in symptom scales such as constipation $(\mathrm{p}=0.009)$, nausea and vomiting $(\mathrm{p}<0.0001)$, dyspnea

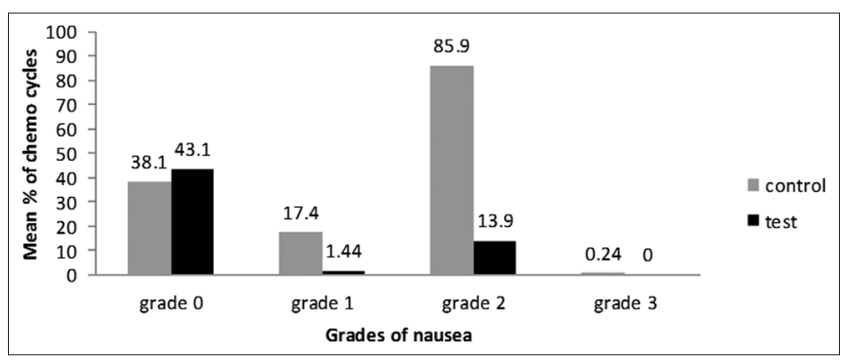

Fig. 1: Mean percentage of chemotherapy cycles with various grades of nausea in the control and study group patients. ${ }^{\text {a Grade } 0}$ denotes patients free of nausea

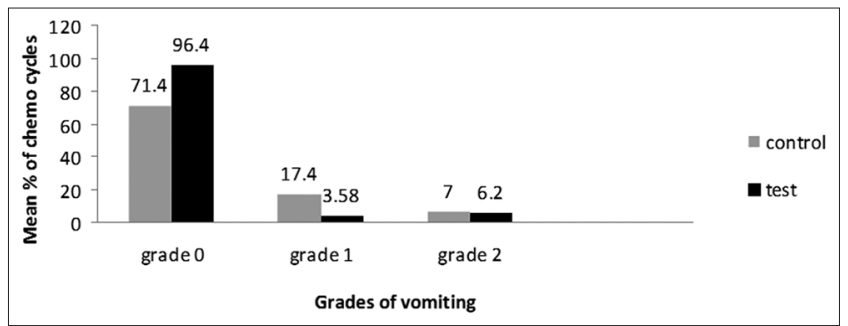

Fig. 2: Mean percentage of chemotherapy cycles with various grades of vomiting in the control ad study group patients. ${ }^{\mathrm{a}} \mathrm{Grade} 0$ denotes patients free of vomiting 
Table 1: Baseline characteristics of the study patients

\begin{tabular}{lll}
\hline Parameters & Control group (n=21) & Study group (n=21) \\
\hline Mean age (years) \pm SD & $54.9 \pm 7.98$ & $51.4 \pm 10.19$ \\
Median age (years) & 53.0 & 51.0 \\
\% of males/females & $14.3 / 85.7$ & $14.3 / 85.7$ \\
\% of patients receiving HEC ${ }^{a}$ & 85.7 & 85.7 \\
\% of patients receiving $\mathrm{MEC}^{\mathrm{b}}$ & 14.3 & 14.3 \\
Cancer type (\% of patients) & & \\
$\quad$ Breast cancer & 61.8 & 61.8 \\
Ovarian cancer & 14.3 & 4.8 \\
Stomach cancer & 9.5 & 9.5 \\
$\quad$ Others & 14.4 & 23.9 \\
Number (\%) of patients receiving various chemotherapy regimens & $13(61.8)$ & $13(61.8)$ \\
Doxorubicin $\left(60 \mathrm{mg} / \mathrm{m}^{2}\right)+$ cyclophosphamide $\left(600 \mathrm{mg} / \mathrm{m}^{2}\right)$ & $1(4.8)$ & $1(4.8)$ \\
Carboplatin $(\mathrm{AUC} 6 \mathrm{mg} / \mathrm{hr} / \mathrm{ml})$ & $2(9.5)$ & $2(9.5)$ \\
Cisplatin $\left(75-100 \mathrm{mg} / \mathrm{m}^{2}\right)$ & $1(4.8)$ & $1(4.8)$ \\
Cisplatin $\left(75 \mathrm{mg} / \mathrm{m}^{2}\right)+$ etoposide $\left(100 \mathrm{mg} / \mathrm{m}^{2}\right)$ & $1(4.8)$ & $1(4.8)$ \\
Epirubicin $\left(50 \mathrm{mg} / \mathrm{m}^{2}\right)+$ oxaliplatin $\left(130 \mathrm{mg} / \mathrm{m}^{2}\right)$ & $3(14.3)$ & $3(14.3)$ \\
Paclitaxel $\left(175 \mathrm{mg} / \mathrm{m}^{2}\right)+$ carboplatin $(\mathrm{AUC} 6 \mathrm{mg} / \mathrm{hr} / \mathrm{ml})$ & \\
\hline
\end{tabular}

${ }^{a}$ HEC: Highly emetogenic chemotherapy, ${ }^{b}$ MEC: Moderately emetogenic chemotherapy, SD: Standard deviation

Table 2: Comparison of chemotherapy cycles of control and study group patients exhibiting nausea during 168 cycles of chemotherapy

\begin{tabular}{llll}
\hline aType of nausea & $\begin{array}{l}\text { Control group (n=84 cycles) } \\
\text { No. (mean \% cycles } \pm \text { SD) }\end{array}$ & $\begin{array}{l}\text { Study group (n=84 cycles) } \\
\text { No. (mean \% cycles } \pm \text { SD) }\end{array}$ & $\begin{array}{l}\text { p value (independent t-test) } \\
\text { Acute }\end{array}$ \\
Delayed & $20(23.8 \pm 10.3)$ & $5(6.0 \pm 6.0)$ & 0.024 \\
Acute+delayed & $19(84.5 \pm 8.1)$ & $29(34.5 \pm 20.7)$ & 0.004 \\
Free of both Acute+delayed & $11(13.1 \pm 7.1)$ & $3(3.6 \pm 2.4)$ & 0.004 \\
\hline
\end{tabular}

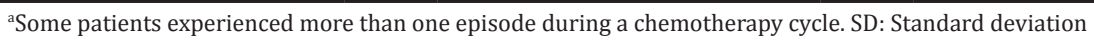

Table 3: Comparison of chemotherapy cycles of control and study group patients exhibiting vomiting during 168 cycles of chemotherapy

\begin{tabular}{llll}
\hline aType of vomiting & \multicolumn{2}{l}{ No. (mean \% cycles \pm SD) } & p value (independent t-test) \\
\cline { 2 - 3 } & Control group (n=84 cycles) & Study group (n=84 cycles) & \\
\hline Acute & $5(6.0 \pm 6.0)$ & $0(0 \pm 0)$ & 0.093 \\
Delayed & $24(40.5 \pm 17.6)$ & $13(15.5 \pm 10.5)$ & 0.051 \\
Acute+delayed & $14(16.7 \pm 6.4)$ & $0(0 \pm 0)$ & 0.264 \\
No acute/delayed & $31(48.8 \pm 4.6)$ & $70(83.3 \pm 12.3)$ & 0.002 \\
\hline
\end{tabular}

aSome patients experienced more than one episode during a chemotherapy cycle. SD: Standard deviation

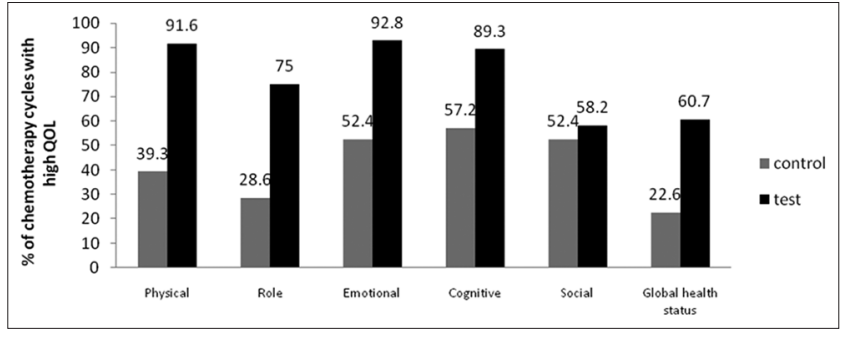

Fig. 3: Percentage of chemotherapy cycles with high quality of life in both control and study group patients showing functional scales and global health status

( $\mathrm{p}=0.009)$, insomnia $(\mathrm{p}=0.009)$, and appetite loss $(\mathrm{p}=0.001)$ as compared to control group patients (Fig. 4). There was also significant improvement in global health status for the study group patients $(\mathrm{p}=0.01)$ in comparison to control group patients.

None of the patients reported any side effect with the use of olanzapine during the four cycles of chemotherapy except for dyspepsia by five patients and dry mouth by six patients in the olanzapine arm and four patients in the control arm. Twelve patients in the olanzapine arm reported improvement in appetite. None of the patients reported any sedation with the use of olanzapine. Similarly, none of the patients in either group had hyperglycemia.

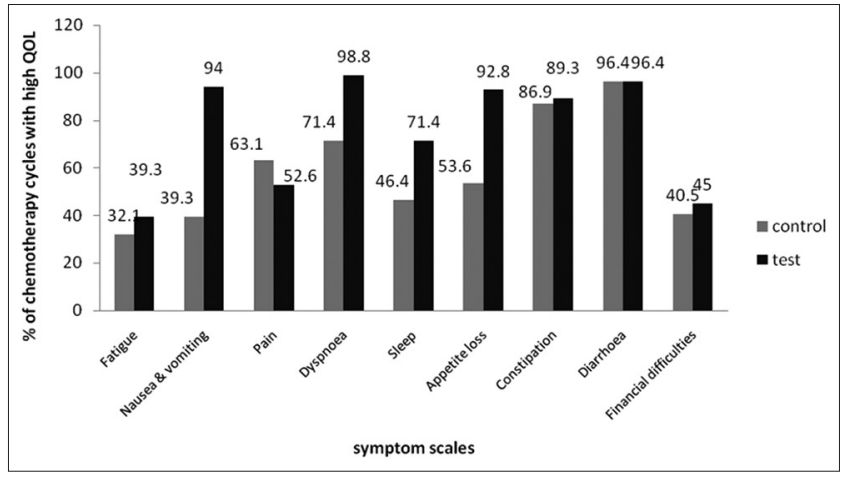

Fig. 4: Percentage of chemotherapy cycles with high quality of life in control and study group patients with respect to symptom scales

\section{DISCUSSION}

The present study evaluated QOL and control of nausea and vomiting in cancer patients who were given olanzapine in addition to the standard antiemetic regimens before highly or moderately emetogenic chemotherapy. Adding olanzapine to the standard antiemetic regimen consisting of a 5-HT3 antagonist, and dexamethasone was more effective than the standard regimen for the prevention of Grade 1 and 
Grade 2 nausea or vomiting. Chemotherapy cycles free of both acute and delayed nausea were significantly more in the olanzapine arm than the control arm. The QOL of the patients in the olanzapine arm showed significant improvement in scores of functional scales such as physical, emotional, role and cognitive functioning, and symptom scales such as nausea and vomiting, dyspnea, insomnia, and appetite loss as compared to those receiving standard antiemetic regimens without olanzapine. Addition of olanzapine also resulted in significant improvement in global health status of the patients. Majority of the patients were free of any adverse effects with the use of olanzapine.

Previous studies [15-20] have shown the efficacy of olanzapine for the prevention of CINV when used in combination with standard antiemetic regimens. A recent phase three trial [28] studied the effect of combining olanzapine with a three drug regimen of dexamethasone, aprepitant or fosaprepitant, and a 5- $\mathrm{HT}_{3}$ receptor antagonist for the prevention of nausea and vomiting in chemotherapy-naïve patients taking HEC. The proportion of patients with no chemotherapy-induced nausea in the olanzapine arm was significantly higher in the first $24 \mathrm{hrs}$ after chemotherapy, the period from 25 to 120 hrs after chemotherapy, and the overall 120-hr period post-chemotherapy. However, in our study, olanzapine was added to a regimen consisting of two drugs, namely, dexamethasone and a 5- $\mathrm{HT}_{3}$ receptor antagonist only. Moreover, that study evaluated the efficacy of olanzapine only for the first cycle of chemotherapy, whereas in our study, the overall effectiveness of olanzapine was evaluated for all the four cycles of chemotherapy. Patients in the olanzapine arm were free of both acute and delayed nausea in $64.3 \%$ (54/84) of chemotherapy cycles, whereas for patients of the control arm, this was achieved only in $13.1 \%$ $(11 / 84)$ of cycles in our study.

Achievement of better control of nausea and vomiting with the use of olanzapine in the absence of aprepitant is a cost-effective strategy for patients of the developing countries in resource poor settings who cannot afford expensive antiemetics such as aprepitant. Olanzapine, an atypical antipsychotic, was approved by the US Food and Drug Administration (FDA) in 1996 for the treatment of schizophrenia and bipolar disorder and generic versions of the drug are available since 2011 and are inexpensive. Olanzapine acts on multiple neurotransmitters [10-12] blocking the action of serotonin at $5 \mathrm{H} 2 \mathrm{a}$, $5 \mathrm{H} 2 \mathrm{c}, 5 \mathrm{H} 3$, and $5 \mathrm{HT} 6$ receptors, dopamine at D1, D2, D3, and D4 brain receptors, catecholamines at alpha 1 adrenergic receptors, acetylcholine at muscarinic receptors $(\mathrm{m} 1, \mathrm{~m} 2, \mathrm{~m} 3$, and $\mathrm{m} 4)$, and histamine at $\mathrm{H} 1$ receptors. The action of olanzapine, especially at D2, 5-HT2c, and 5-HT3 receptors which are involved in mediation of nausea and vomiting makes it a good candidate for control of CINV. It is effective for both acute and delayed CINV due to its action at multiple neurotransmitters. The long half-life (21-54 hrs) of olanzapine [29] permits once daily dosing and may contribute to increased patient compliance. A Phase II study [16] also showed that olanzapine combined with a single dose of dexamethasone, and a single dose of palonosetron was very effective in controlling acute and delayed CINV in patients receiving both HEC and MEC. A recent study [30] evaluated the efficacy, safety, and cost benefit of olanzapine as compared to aprepitant for the prevention of CINV in patients receiving palonosetron and dexamethasone combination regimens. There was no difference in safety and efficacy but olanzapine was a cost-effective alternative to aprepitant.

In both the control as well as olanzapine arms, $85 \%$ of our patients were females. $33.3 \%(7 / 21)$ and $47.6 \%(10 / 21)$, respectively, of the patients were below 50 years of age. Both female gender [31] and age $<50$ years [32] are risk factors for CINV. Although the HEC drug cisplatin was administered only to $14.3 \%$ of patients in both arms, $61.8 \%$ of patients in both the arms received a combination of doxorubicin and cyclophosphamide. Administered individually, cyclophosphamide $\left(<1500 \mathrm{mg} / \mathrm{m}^{2}\right)$ and doxorubicin are only moderately emetogenic, but their combination is considered highly emetogenic [33], especially in women with breast cancer [34] and $61.8 \%$ of our patients were treated for cancer of the breast. Hence, majority of our patients $(86.3 \%)$ received HEC. The remaining had MEC.
In all the four cycles of chemotherapy from day 1-5 taken together, significantly more number of patients in the study group were free from nausea as compared to the control group patients. There were no patients with Grade 3 nausea in the study group and only a few patients (5/84) in control group. There was a significant decrease in the number of patients with Grade 1 and 2 nausea in the study group as compared to the control group patients. Grade 3 and 4 vomiting were absent in the entire cohort of patients. In all the 84 cycles of chemotherapy taken together, there was a significant decrease in the number of patients with vomiting in the study group as compared to the control group. Similarly, there was significant increase in the number of patients free of vomiting in the study group as compared to the control group patients.

The EORTC QOL questionnaire is a structured tool with 30 questions designed for heterogeneous group of cancer patients. The QLQ-C30 is composed of five functional scales, three symptom scales (fatigue, pain, and nausea), a global health status scale, and six single items which describe cancer-oriented symptoms. All of the scales and single-item measures range in score from 0 to 100 . A high score represents a higher response level. Thus, a high score for a functional scale represents a high/healthy level of functioning, a high score (ranging 50-100) for the global health status represents a high QOL, but a high score (50-100 score) for a symptom scale/item represents a high level of symptomatology/problems [23]. A decreased score for any of the symptom scales represents an improvement of symptomatic problem.

Prevention of CINV can improve cancer patient's QOL and activities of daily living. Delayed CINV can severely impair the QOL of patients [1]. The overall assessment of QOL after chemotherapy of the study patients showed a significant improvement in scores of functional scales such as physical, emotional, role and cognitive functioning, and symptom scales such as nausea and vomiting, dyspnea, insomnia, appetite loss. The Global Health Status also increased significantly. A study [15] by Tan et al. also found significant improvement in global health status, social functioning, fatigue, nausea and vomiting, insomnia, and appetite loss in patients receiving a three drug regimen consisting of azasetron, dexamethasone, and olanzapine for the prevention of CINV due to HEC or MEC. But in our study, with respect to social functioning and fatigue, there was no improvement in QOL scores.

In a phase three trial [28] by Navari et al., some patients who received olanzapine experienced tiredness and sedation, especially on the second day which resolved with continued use of the drug in subsequent days. However, none of the 21 patients in our study reported any adverse effect of sedation with the use of olanzapine during the 4 cycles of chemotherapy, but five patients reported dyspepsia and dry mouth by six patients. Other side effects of olanzapine such as diabetes [35] and weight gain $[36,37]$ may not be evident with the short-term use of the drug. Drug reaction with eosinophilia and systemic symptoms (DRESS) has been recently added by the US FDA [38] as a warning sign to the drug label of olanzapine. DRESS is a rare but serious skin reaction, and the patients develop fever with a rash and swollen lymph glands or swelling in the face. However, our patients were free of DRESS syndrome.

The small sample size is a limitation of our study. The effectiveness of olanzapine for control of nausea and vomiting caused by radiation therapy to the brain, upper abdomen, or due to total body radiation therapy as in stem cell transplants or when chemotherapy is given along with radiation can be explored in the future.

\section{CONCLUSION}

Addition of olanzapine to standard antiemetic regimen of dexamethasone and a 5- $\mathrm{HT}_{3}$ receptor antagonist can improve control of nausea and vomiting and at the same time improve the QOL of patients receiving highly or moderately emetogenic chemotherapeutic agents as compared to patients receiving standard pre-medication regimens without olanzapine. 


\section{ACKNOWLEDGMENTS}

We are indebted to the patients who participated in this study. We are also thankful to EORTC QOL Department, Ave. E. Mounier 83, B.11, 1200 Brussels, Belgium, for permission to use EORTC QOL C30 questionnaire in English and for its Malayalam version and for the scoring manuals. We are also grateful to Dr. Shantikumar V Nair, Dean of Research, Amrita University, for motivation and encouragement.

\section{REFERENCES}

1. Bloechl-Daum B, Deuson RR, Mavros P, Hansen M, Herrstedt J. Delayed nausea and vomiting continue to reduce patients' quality of life after highly and moderately emetogenic chemotherapy despite antiemetic treatment. J Clin Oncol 2006;24(24):4472-8.

2. Hilal MA. Chemotherapy induced nausea and vomiting: The role of aprepitant. Middle East J Cancer 2011;2:3-8

3. Antony A, Joel JJ, Shetty J, Umar NF. Identification and analysis of adverse drug reactions associated with cancer chemotherapy in hospitalized patients. Int J Pharm Pharm Sci 2016;8:448-51.

4. Drisya PM, James E. Recent updates in the management of chemotherapy induced nausea and vomiting. Asian J Pharm Clin Res 2013;6 Suppl 4:5-10.

5. Rusthoven JJ, Osoba D, Butts CA, Yelle L, Findlay H, Grenville A. The impact of postchemotherapy nausea and vomiting on quality of life after moderately emetogenic chemotherapy. Support Care Cancer 1998;6(4):389-95.

6. Guyatt GH, Feeny DH, Patrick DL. Measuring health-related quality of life. Ann Intern Med 1993;118(8):622-9.

7. Ballatori E, Roila F. Impact of nausea and vomiting on quality of life in cancer patients during chemotherapy. Health Qual Life Outcomes 2003;1:1-11.

8. Drechsler S, Bruntsch U, Eggert J, Grote-Kiehn J, Gosse H, Bangerter M, et al. Comparison of three tropisetron-containing antiemetic regimens in the prophylaxis of acute and delayed chemotherapy-induced emesis and nausea. Support Care Cancer 1997;5(5):387-95.

9. Feyer P, Jordan K. Update and new trends in antiemetic therapy: The continuing need for novel therapies. Ann Oncol 2011;22(1):30-8.

10. Bymaster FP, Nelson DL, DeLapp NW, Falcone JF, Eckols K, Truex LL, et al. Antagonism by olanzapine of dopamine D1, serotonin2, muscarinic, histamine $\mathrm{H} 1$ and alpha 1-adrenergic receptors in vitro. Schizophr Res 1999;37(1):107-22

11. Zhang W, Bymaster FP. The in vivo effects of olanzapine and other antipsychotic agents on receptor occupancy and antagonism of dopamine D1, D2, D3, 5HT2A and muscarinic receptors. Psychopharmacology (Berl) 1999;141(3):267-78

12. Bymaster FP, Falcone JF, Bauzon D, Kennedy JS, Schenck K, DeLapp NW, et al. Potent antagonism of 5-HT(3) and 5-HT(6) receptors by olanzapine. Eur J Pharmacol 2001;430(2-3):341-9.

13. Dubé S, Tollefson GD, Thase ME, Briggs SD, Van Campen LE, Case $\mathrm{M}$, et al. Onset of antidepressant effect of olanzapine and olanzapine/fluoxetine combination in bipolar depression. Bipolar Disord 2007;9(6):618-27.

14. Ghaemi SN, Cherry EL, Katzow JA, Goodwin FK. Does olanzapine have antidepressant properties? A retrospective preliminary study. Bipolar Disord 2000;2:196-9.

15. Tan L, Liu J, Liu X, Chen J, Yan Z, Yang H, et al. Clinical research of Olanzapine for prevention of chemotherapy-induced nausea and vomiting. J Exp Clin Cancer Res 2009;28:131.

16. Navari RM, Einhorn LH, Loehrer PJ Sr, Passik SD, Vinson J, McClean J, et al. A phase II trial of olanzapine, dexamethasone, and palonosetron for the prevention of chemotherapy-induced nausea and vomiting: A Hoosier oncology group study. Support Care Cancer 2007;15:1285-91.

17. Mizukami N, Yamauchi M, Koike K, Watanabe A, Ichihara K, Masumori N, et al. Olanzapine for the prevention of chemotherapyinduced nausea and vomiting in patients receiving highly or moderately emetogenic chemotherapy: A randomized, double-blind, placebocontrolled study. J Pain Symptom Manage 2014;47(3):542-50.
18. Navari RM, Gray SE, Kerr AC. Olanzapine versus aprepitant for the prevention of chemotherapy-induced nausea and vomiting: A randomized phase III trial. J Support Oncol 2011;9(5):188-95.

19. Wang X, Wang L. Effectiveness of olanzapine in prevention of chemotherapy induced nausea and vomiting. Clin J Clin 2012;6:7406-7.

20. Lu YL, Liu W, Du YJ. Antiemetic effect of low dose olanzapine in solid tumor chemotherapy. Clin J Cancer Prev Treat 2013;20:544-54.

21. Noviyani R, Indrayathi PA, Budiana IN, Suwiyoga K, Tunas K. Assessment of life quality in patients with stage IIB-IIIB squamous cell cervical cancer receiving paclitaxel cisplatin chemotherapy regimen by eortc QLQ-C30 questionnaire in sanglah hospital denpasar. Int J Pharm Pharm Sci 2017:9:222-6.

22. Aaronson NK, Ahmedzai S, Bergman B, Bullinger M, Cull A, Duez NJ, et al. The European organization for research and treatment of cancer QLQ-C30: A quality-of-life instrument for use in international clinical trials in oncology. J Natl Cancer Inst 1993;85(5):365-76.

23. Michelson $\mathrm{H}$, Bolund C, Nilsson B, Brandberg Y. Health-related quality of life measured by the EORTC QLQ-C30-reference values from a large sample of Swedish population. Acta Oncol 2000;39(4):477-84

24. Available from: http://www.groups.eortc.be/qol. [Last accessed on 2012 Jun 11].

25. Common Terminology Criteria for Adverse Events (CTCAE). Version 4.0.National Institutes of Health National Cancer Institute; 2009. Available from: http://www.eortc.be//doc//CTCAE 4.03 2010-06-14 QuickReference_5x7. [Last accessed on 2013 May 16]

26. Hesketh PJ. Comparative review of 5-HT3 receptor antagonists in the treatment of acute chemotherapy-induced nausea and vomiting. Cancer Invest 2000;18(52):163-73

27. Yalcin S, Tekuzman G, Baltali E, Ozisik Y, Barista I. Serotonin receptor antagonists in prophylaxis of acute and delayed emesis induced by moderately emetogenic, single-day chemotherapy: A randomized study. Am J Clin Oncol 1999;22(1):94-6.

28. Navari RM, Qin R, Ruddy KJ, Liu H, Powell SF, Bajaj M, et al. Olanzapine for the Prevention of chemotherapy-induced nausea and vomiting. N Engl J Med 2016;375(2):134-42.

29. Available from: https://www.uptodate.com/contents/olanzapinedrug-information? source $=$ search_result $\&$ search $=$ olanzapine $\% 20$ adult\&selectedTitle $=1 \sim 130$. [Last accessed on 2017 Jan 24]

30. Babu G, Saldanha SC, Chinnagiriyappa LK, Jacob LA, Mallekavu SB, Dasappa L, et al. The efficacy, safety, and cost benefit of olanzapine versus aprepitant in highly emetogenic chemotherapy: A pilot study from South India. Chemother Res Pract 2016;2016:3439707.

31. Sekine I, Segawa Y, Kubota K, Saeki T. Risk factors of chemotherapyinduced nausea and vomiting: Index for personalized antiemetic prophylaxis. Cancer Sci 2013;104(6):711-7.

32. Schwartzberg LS. Chemotherapy-induced nausea and vomiting: Clinician and patient perspectives. J Support Oncol 2007;5 2 Suppl 1:5-12.

33. Basch E, Prestrud AA, Hesketh PJ, Kris MG, Feyer PC, Somerfield MR, et al. Antiemetics: American society of clinical oncology clinical practice guideline update. J Clin Oncol 2011;29(31):4189-98.

34. Warr DG, Street JC, Carides AD. Evaluation of risk factors predictive of nausea and vomiting with current standard-of-care antiemetic treatment: Analysis of phase 3 trial of aprepitant in patients receiving adriamycin-cyclophosphamide-based chemotherapy. Support Care Cancer 2011;19:807-13

35. Seaburg HL, McLendon BM, Doraiswamy PM. Olanzapine-associated severe hyperglycemia, ketonuria, and acidosis: Case report and review of literature. Pharmacotherapy 2001;21(1):1448-54.

36. Allison DB, Casey DE. Antipsychotic-induced weight gain: A review of the literature. J Clin Psychiatry 2001;62 Suppl 7:22-31

37. Hale AS. Olanzapine. Br J Hosp Med 1997;58:442-5.

38. FDA. Olanzapine: Drug Safety Communication-FDA Warns about Rare But Serious Skin Reactions. Available from: http://www.fda.gov/Safety/MedWatch/SafetyInformation/ SafetyAlertsforHumanMedicalProducts/ucm500123.htm. [Last accessed on 2017 Jan 18]. 